\title{
Prevalência e estudo genético de Mycoplasma gallisepticum e $M$. synoviae em poedeiras comerciais, na região centro-oeste do estado de São Paulo, Brasil
}

[Prevalence and genetic study of Mycoplasma gallisepticum and M. synoviae strains from commercial laying hens in the Midwest region of Sao Paulo state, Brazil]

R.L. Silva $a^{1}$, M.M. Silva ${ }^{2}$, A.A. Figueira ${ }^{2}$, L.S. Machado ${ }^{1,2}$, N.C. Cunha ${ }^{2}$, T.S. Dias $^{1}$, N.M. Soares ${ }^{3}$, E.R. Nascimento ${ }^{1,2}$, V.L.A. Pereira ${ }^{1,2}$

${ }^{1}$ Programa de Pós-Graduação - Faculdade de Veterinária - Universidade Federal Fluminense - Niterói, RJ ${ }^{2}$ Faculdade de Veterinária - Universidade Federal Fluminense - Niterói, RJ

${ }^{3}$ Instituto Biológico - Bastos, SP

\section{RESUMO}

O objetivo deste trabalho foi estudar a prevalência de MG e MS e a filogenia das cepas circulantes, comparando-as com outras já descritas em poedeiras comerciais no Brasil. Foram coletados 140 suabes traqueais de poedeiras comerciais com sinais respiratórios em seis granjas da região centro-oeste de São Paulo. As amostras foram avaliadas por PCR, com posterior sequenciamento e análise filogenética das cepas identificadas. Das 140 amostras, 16,4\% foram positivas para MG e 68,6\% para MS. Houve diferença significativa nas frequências de MG e MS por granja, segundo o teste $\mathrm{G}$ de independência $(\mathrm{P}<0,05)$. Todas as cepas identificadas de MG e MS de granjas distintas apresentaram similaridade tanto pela lipoproteína para MG quanto pela região 16s rRNA para MS. Neste estudo, foi possível observar altas prevalências dos agentes estudados, sendo a de MS maior que a de MG. Foi detectada infecção mista por MG e MS em $11,4 \%$ das amostras e sabe-se que esses micoplasmas podem agir de forma sinérgica, agravando o quadro respiratório. As cepas circulantes identificadas, pela análise das regiões gênicas da lipoproteína para MG e 16S rRNA para MS, são similares em todas as granjas estudadas.

Palavras-chave: micoplasmas, poedeiras, quadro respiratório, filogenia

\begin{abstract}
The aim of this study was to evaluate the prevalence of $M G$ and $M S$ and the phylogeny of the circulating strains, comparing them with others already described in commercial laying hens from Brazil. A total of 140 tracheal swabs were collected from commercial laying hens with respiratory signs in six farms from the western region of São Paulo state. The samples were analyzed by PCR with subsequent sequencing and phylogenetic analysis of the identified strains. From the 140 samples, 68.6\% were positive for MS and $16.4 \%$ for MG. There was a significant difference in the frequencies of $M G$ and $M S$ per farm according to $G$ Test of independence $(P<0.05)$. All strains identified as $M G$ and $M S$ from distinct farms presented similarity both by lipoprotein to MG and by $16 \mathrm{~s}$ rRNA region to MS. In this study, it was possible to observe a high prevalence of MS compared to MG. Mixed MG and MS infection was detected in 11.4\% of the samples. These mycoplasmas may act synergistically, worsening the respiratory signs. The circulating strains identified by analysis of the lipoprotein for MG and 16S rRNA for MS are similar on all poultry farms studied.
\end{abstract}

Keywords: mycoplasmas, laying hens, respiratory disease, phylogeny

\section{INTRODUÇÃO}

O Brasil ocupa a sexta posição dentre os maiores produtores de ovos do mundo, porém grande parte da produção brasileira continua destinada apenas ao consumo interno (ABPA, 2018). Diante disso, o setor possui grandes perspectivas de expansão nos mercados nacional e internacional, sendo a preocupação com sanidade e biosseguridade dos plantéis avícolas um dos pilares em sua

Recebido em 16 de julho de 2019

Aceito em 10 de dezembro de 2019

E-mail: rosiane_lima@id.uff.br 
estruturação. Entretanto, as doenças respiratórias ainda são um desafio para a avicultura industrial, destacando-se a micoplasmose aviária como uma das doenças de maior impacto econômico em todos os níveis da atividade avícola.

Micoplasmas são os menores procariontes conhecidos, possuindo como características marcantes ausência de parede celular e dependência do colesterol para o seu metabolismo (Nascimento e Pereira, 2009). Dentre as espécies de micoplasmas que acometem as aves de produção, destacam-se Mycoplasma gallisepticum (MG) e Mycoplasma synoviae (MS), associados a doenças subclínicas ou aparentes em galinhas. MG e MS possuem distribuição universal e sua transmissão pode ocorrer horizontalmente - por contato direto com outras aves ou indireto, por meio de aerossóis, pessoas, animais, ração, água e equipamentos - ou via ovo, caracterizando a transmissão vertical. As lesões e os sinais clínicos são confinados principalmente ao trato respiratório, podendo-se observar espirros, tosse, estertores, corrimento nasal, inchaço e edema de face, lacrimejamento, blefarite, conjuntivite e queda nos índices zootécnicos em aves de postura, ou até lesões mais graves, como traqueíte, bronquite, pneumonia e aerossaculite (Nascimento e Pereira, 2009; Noel-Ferguson, 2013).

Diversas cepas de MG e MS com diferentes graus de patogenicidade, virulência e imunogenicidade já foram diferenciadas fenotípica e genotipicamente, justificando a variação na severidade da doença. (Nascimento e Yamamoto, 1991; Nascimento et al., 2005; Noel-Ferguson e Noormohammadi, 2013; Raviv e Ley, 2013). O genoma dos micoplasmas engloba sistemas complexos para a regulação gênica e, consequentemente, na variação da estrutura e da expressão de produtos de genes específicos, sendo importante para a adaptação e a patogenicidade dos micoplasmas (Yogev et al., 1991; Rosengarten et al., 1994; Rosengarten e Yogev, 1996; Razin et al., 1998).

O diagnóstico da infecção por micoplasmas pode ser realizado pela associação entre a análise dos dados zootécnicos, a observação dos sinais clínicos e das lesões anatomopatológicas e, etiologicamente, por meio de testes sorológicos, isolamento e técnicas biomoleculares, como a técnica de reação da polimerase em cadeia
("Polymerase Chain Reaction" - PCR) (Umar et al., 2017; Nascimento e Pereira, 2009). Diversos estudos demonstram que a PCR apresenta sensibilidade maior que os testes sorológicos e o isolamento, além de uma viabilidade econômica que vem atraindo a implantação desse método nas rotinas dos laboratórios de diagnóstico para monitoramento (Muhammad et al., 2018; Gondal et al., 2015; Islam et al., 2011; Buim et al., 2009). A frequente variação antigênica e reação cruzada de algumas espécies do gênero Mycoplasma tornam trabalhosa a classificação convencional das estirpes de bactérias desse gênero por critérios fenotípicos (Poveda, 2010), sendo, portanto, essencial o uso de métodos moleculares como o sequenciamento.

O objetivo deste trabalho foi estudar a prevalência de MG e MS e a filogenia das cepas circulantes, comparando-as com outras já descritas em poedeiras comerciais, na região centro-oeste do estado de São Paulo, Brasil.

\section{MATERIAL E MÉTODOS}

O projeto foi submetido ao Comitê de Ética em Uso de Animais da Universidade Federal Fluminense e aprovado sob número 1004.

Foram realizadas coletas de amostras em dois lotes, em cinco granjas diferentes (A, B, C, D e E) de poedeiras comerciais do tipo convencional. $\mathrm{Na}$ sexta granja $(\mathrm{F})$, foram coletadas amostras de quatro lotes. Todas as granjas estavam localizadas na região centro-oeste de São Paulo. Foram obtidas amostras de suabe traqueal de 10 galinhas de cada lote, totalizando 140 amostras. Observouse que as aves de todas as granjas apresentavam sinais clínicos, como espirros, tosse, estertores e corrimento nasal. Os suabes traqueais foram acondicionados em microtubos contendo meio líquido de Frey modificado (Nascimento e Pereira, 2009) glicerinado a 50\%, armazenados e transportados sob refrigeração aos Laboratórios de Sanidade Avícola e Epidemiologia Molecular da Faculdade de Veterinária da UFF, onde foram processados.

A partir dos suabes traqueais imersos em meio Frey modificado, foi realizada a extração de DNA pelo método fenol-clorofórmio adaptado de Sambrook et al. (1989). Posteriormente, todas as amostras foram submetidas à PCR para detecção de MG e MS. 
Para detecção de $\mathrm{MG}$, a reação conteve: $1 \mathrm{X}$ de PCR buffer; $2 \mathrm{mM}$ de $\mathrm{MgCl} 2 ; 0,2 \mathrm{mM}$ de dNTP; 0,2nmol de cada primer específico (Tab. 1); 1U de Taq Polimeras (Platinum Taq DNA Polimerase, Thermo Fisher Scientific, Waltham, Massachusetts, EUA) e 20ng do DNA extraído, em volume de $25 \mu \mathrm{L}$. A PCR MG foi realizada nas seguintes condições: $95^{\circ} \mathrm{C}$ por cinco minutos, seguidos de 40 ciclos de $95^{\circ} \mathrm{C}$ por um minuto, $55^{\circ} \mathrm{C}$ por dois minutos e $72^{\circ} \mathrm{C}$ por um minuto, com uma fase final de $72^{\circ} \mathrm{C}$ por cinco minutos.

Para MS, a reação conteve 1X PCR buffer $(10 \mathrm{mM}$ de Tris- $\mathrm{HCl}, \mathrm{pH}$ 8,0 e 50mM de $\mathrm{KCl}) ; 1,5 \mathrm{mM}$ de
$\mathrm{MgCl} 2 ; \quad 0,2 \mathrm{mM}$ de trifosfato de desoxirribonucleotídeos (dNTP); 0,2nmol de cada primer específico (Tab. 2); 1,25U de Taq Polimerase (Platinum Taq DNA Polimerase, Thermo Fisher Scientific, Waltham, Massachusetts, EUA) e 20ng do DNA extraído, em volume de $25 \mu \mathrm{L}$. A PCR MS foi realizada nas seguintes condições: $94^{\circ} \mathrm{C}$ por um minuto, seguidos de 40 ciclos de $94^{\circ} \mathrm{C}$ por 30 segundos, $55^{\circ} \mathrm{C}$ por 30 segundos e $72^{\circ} \mathrm{C}$ por um minuto, com uma fase final de $72^{\circ} \mathrm{C}$ por cinco minutos. Como controle, foram utilizadas as cepas MS ATCC 25204, MG ATCC 129 S6 e água ultrapura.

Tabela 1. Oligonucleotídeos iniciadores (primers) para a realização de PCR na detecção de micoplasmas aviários com suas sequências, tamanho do produto amplificado e referência

\begin{tabular}{|c|c|c|c|}
\hline $\begin{array}{l}\text { Primers } \\
*\end{array}$ & Sequência & Produto & Referência \\
\hline MsppF1 & 5'CGCCTGAGTAGTACGTTCGC3' & \multirow{9}{*}{$\begin{array}{l}510- \\
520 \mathrm{pb}\end{array}$} & \multirow{9}{*}{ UPHOFF e DREXLER, 2002} \\
\hline MsppF2 & 5'CGCCTGAGTAGTACGTACGC3' & & \\
\hline MsppF3 & 5’TGCCTGAGTAGTACATTCGC3’ & & \\
\hline MsppF4 & 5’TGCCTGGGTAGTACATTCGC3' & & \\
\hline MsppF5 & 5’CGCCTGGGTAGTACATTCGC3' & & \\
\hline MsppF6 & 5’CGCCTGAGTAGTATGCTCGC3' & & \\
\hline MsppR1 & 5’GCGGTGTGTACAAGACCCGA3' & & \\
\hline MsppR2 & 5’GCGGTGTGTACAAAACCCGA3' & & \\
\hline MsppR3 & 5'GCGGTGTGTACAAACCCCGA3' & & \\
\hline MG-f & 5’CGTGGATATCTTTAGTTCCAGCTGC3' & \multirow{2}{*}{$481 \mathrm{pb}$} & \multirow{2}{*}{ Nascimento et al., 1991} \\
\hline MG-r & 5'GTAGCAAGTTATAATTTCCAGGCAT3' & & \\
\hline MS-f & 5’GAGAAGCAAAATAGTGATATCA3' & \multirow{2}{*}{$207 \mathrm{pb}$} & \multirow{2}{*}{ Lauerman et al., 1993} \\
\hline MS-r & 5'CAGTCGTCTCCGAAGTTAACAA3' & & \\
\hline
\end{tabular}

Os produtos da PCR foram aplicados em gel de agarose a $1,5 \%$, submerso em tampão Trisacetato-EDTA (TAE), submetidos à corrida eletroforética, corados em Gel $\operatorname{Red}^{\circledR}$, e a visualização foi realizada sob luz ultravioleta em transiluminador.

Duas amostras positivas à PCR de cada lote para MG ou MS foram amplificadas segundo Uphoff e Drexler (2002), para se obterem produtos da PCR maiores. O produto da PCR foi purificado pelo kit Wizard $^{\circledR}$ SV Genomic DNA
Purification System (Promega), e o material enviado à Plataforma de Sequenciamento subunidade RPT01A, do Instituto Oswaldo Cruz, onde as sequências de nucleotídeos forward e reverse foram determinadas, utilizando-se o sequenciador ABI3730 automático (Applied Biosystems $^{\circledR}$, Foster City, Califórnia, EUA). As sequências dos genes foram ajustadas para qualidade e montadas em contigs com o software BioEdit ${ }^{\circledR}$ (version 7.0.5; downloaded from http://www.mbio.ncsu.edu/bioedit/bioedit.h tml). As sequências consensus resultantes foram 
usadas para a análise de nucleotídeos BLAST (Basic Local Alignment Search Tool) no banco de dados do NCBI, a fim de determinar a similaridade com as espécies da classe Mollicutes. A história evolutiva foi inferida usando-se o método da máxima verossimilhança e o modelo Kimura de dois parâmetros. A árvore com a maior probabilidade de $\log$;-2594.43 é mostrada. A porcentagem de árvores nas quais a taxa associada é agrupada é mostrada ao lado das ramificações. As análises evolutivas foram geradas usando-se o software Mega X, versão 6.06 (Tamura et al., 2013).

\section{RESULTADOS E DISCUSSÃO}

Do total de 140 amostras de galinhas obtidas das seis granjas de poedeiras comerciais analisadas à PCR, 16,4\% (23/140) foram positivas para MG e $68,6 \%$ (96/140) apresentaram resultado positivo para MS (Tab. 2). Houve diferença significativa entre as frequências de MG e MS por granja (teste $G$ de independência $P<0,05)$, sendo a maior frequência encontrada para MS de $100 \%$ na granja C, e a menor de $37,5 \%$ na granja F. Para MG, essa variação foi de $65 \%$ na granja $\mathrm{E}$ e de $0 \%$ nas granjas B e F. Todas as granjas apresentaram maior frequência de $\mathrm{MS}$ em relação a $\mathrm{MG}$, com exceção da granja $\mathrm{E}$, que apresentou $65 \%$ de MG e $55 \%$ de MS. Este estudo demonstrou uma alta prevalência de MG e MS, diferentemente de estudos realizados por Buim et al. (2009) e Teixeira et al. (2015). O estudo feito por Buim et al. (2009) descreveu prevalência de $0 \%$ para MG e de 15,15\% para MS em 1046 amostras de galinhas com doença respiratória e/ou queda na produção de ovos provenientes dos estados de São Paulo, Paraná e Pernambuco. Já Teixeira et al. (2015), ao avaliarem 115 amostras de suabe traqueal de poedeiras comerciais no Rio de Janeiro, encontraram 2,6\% (3/115) positivos para MG e $20,86 \%$ (24/115) para MS.

A alta ocorrência de MS nas aves demonstra a presença da infecção, já que a vacinação contra esse agente não é prática comum nas granjas estudadas. O controle de MS por vacinação não é difundido no Brasil, porém programas vacinais para MG são amplamente usados nas granjas poedeiras, o que justificaria sua menor ocorrência.

Tabela 2. Frequência de M. gallisepticum e Mycoplasma synoviae identificados pela PCR nas granjas de poedeiras comerciais, na região centro-oeste do estado de São Paulo, Brasil

\begin{tabular}{llllllll}
\hline PCR & Granja A & Granja B & Granja C & Granja D & Granja E & Granja F & Total \\
\hline MG* $^{*}$ & $10 \%$ & $0 \%$ & $5 \%$ & $35 \%$ & $65 \%$ & $0 \%$ & $16,4 \%$ \\
& $(2 / 20)$ & $(0 / 20)$ & $(1 / 20)$ & $(7 / 20)$ & $(13 / 20)$ & $(0 / 40)$ & $(23 / 140)$ \\
& $75 \%$ & $95 \%$ & $100 \%$ & $80 \%$ & $55 \%$ & $37,5 \%$ & $68,6 \%$ \\
MS* & $(15 / 20)$ & $(19 / 20)$ & $(20 / 20)$ & $(16 / 20)$ & $(11 / 20)$ & $(15 / 40)$ & $(96 / 140)$ \\
\hline
\end{tabular}

* MG-Mycoplasma gallisepticum; MS - Mycoplasma synoviae.

Das amostras analisadas, $11,4 \% \quad(16 / 140)$ apresentaram, à PCR, infecção mista por MG e MS, semelhantmentee ao estudo de Buim et al. (2009), que detectaram a infecção concomitante por esses micoplasmas aviários em $18,18 \%$ das aves estudadas pela Multiplex PCR. O sinergismo entre agentes respiratórios, incluindo os micoplasmas, pode exacerbar os quadros respiratórios (Hutton et al., 2017; Sid et al., 2015), o que torna relevante os resultados obtidos.

Em relação ao sequenciamento da região da lipoproteína de MG, as cepas MK936069, da granja D, MK936070 e MK 936071, da granja E, foram correlatas pela análise ao BLAST e apresentaram percentual de correlação superior a $97,42 \%$, o que fez com que permanecessem no mesmo cluster. Já as cepas MK936067 e MK936068, provenientes das granjas C e D, foram diferentes entre si e também das citadas anteriormente, com percentual de correlação de 94,04\%, pertencendo a outro cluster. As cepas de campo MK936067, MK936068, MK936069, MK936070 e MK 936071, identificadas no presente estudo, são distintas das cepas vacinais ts-11 e F quando avaliadas pela árvore filogenética (Fig. 1). 


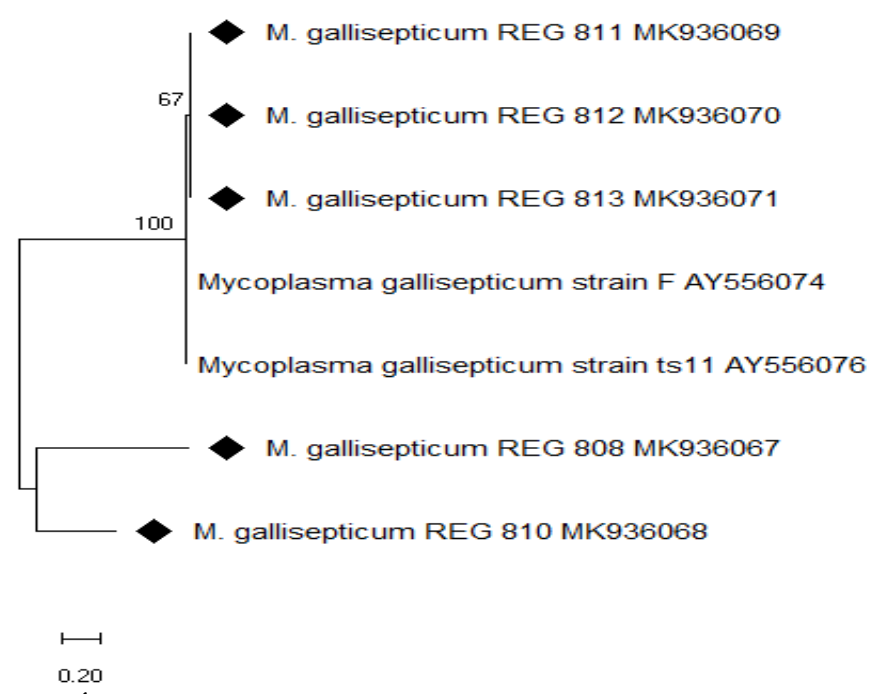

Figura 1. Árvore filogenética de M. gallisepticum comparando cepas circulantes na região centro-oeste de São Paulo e cepas vacinais desenvolvidas pelo método máxima verossimilhança e pelo modelo Kimura (1980) de dois parâmetros, com base nos fragmentos do gene da lipoproteína. Análises evolucionárias foram realizadas no software Mega X.

Pelo sequenciamento da região do 16s rRNA para Mollicutes, foi possível observar a presença de uma mesma cepa de MS circulando nas granjas avaliadas. Pela análise ao BLAST, as cepas MK922528, MK922561, MK922563 e MK922565 apresentaram $100 \%$ de similaridade entre si, sendo identificadas nas granjas A, C, D e F. Essas cepas ainda possuem similaridade variando de $98,53 \%$ a $100 \%$ com a cepa DQ497544 e de $88,44 \%$ a $98,11 \%$ com a cepa DQ497 identificadas por Buim et al. (2010), ao avaliarem a região $16 \mathrm{~S}$ rRNA de $\mathrm{MS}$ em poedeiras comerciais na região de Bastos, São Paulo. Já a cepa MK922564 possui similaridade de $96,41 \%$ com as demais cepas identificadas neste estudo, sugerindo um provável ancestral comum (Fig. 2). Esses dados corroboram o trabalho de Buim et al. (2010), que, após avaliarem 10 cepas de MS isoladas de poedeiras de diferentes granjas, descreveram a presença de quatro cepas semelhantes na mesma região. A cepa padrão MS NR_044811 possuiu similaridade variando de $94,72 \%$ a $99,34 \%$ com as cepas encontradas em todas as granjas avaliadas (Fig. 2).

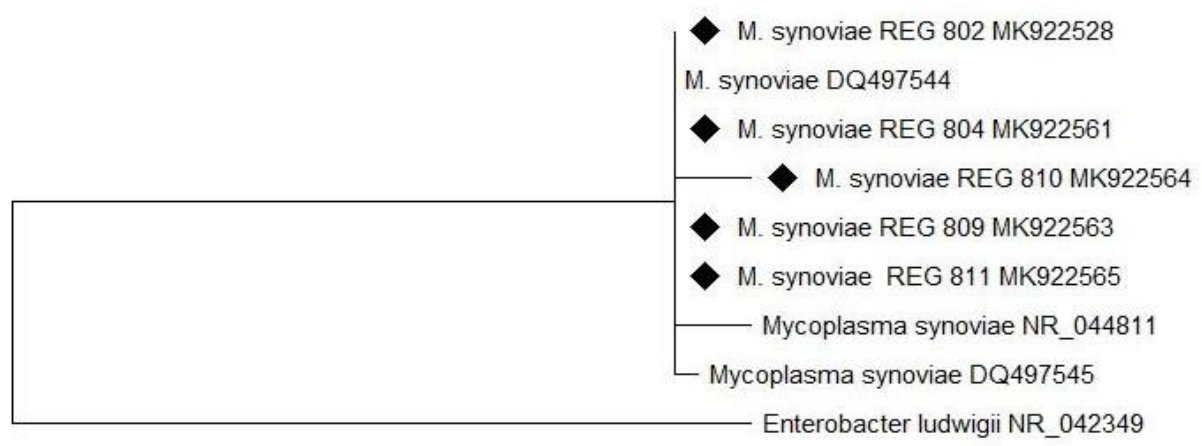

0.10

Figura 2. Árvore filogenética de $M$. synoviae identificados na região centro-oeste de São Paulo, desenvolvida pelo método máxima verossimilhança e pelo modelo Kimura (1980) de dois parâmetros, com base nos fragmentos amplificados da região gênica 16s rRNA. Análises evolucionárias foram realizadas no software Mega X. 


\section{CONCLUSÃO}

Foram observadas altas prevalências de MG e MS nas granjas de poedeiras avaliadas na região centro-oeste de São Paulo, Brasil, sendo a de MS maior que a de MG. Foi detectada infecção mista por MG e MS. Pela análise das regiões gênicas da lipoproteína para MG e 16S rRNA para MS, conclui-se que as cepas circulantes dessas espécies de micoplasmas foram similares em todas as granjas estudadas.

\section{REFERÊNCIAS}

BUIM, M. R.; METTIFOGO, E.; TIMENETSKY, J. et al. Epidemiological survey on Mycoplasma gallisepticum and $M$. synoviae by multiplex PCR in commercial poultry. Pesqui. Vet. Bras., v.29, p.552-556, 2009.

BUIM, M.R.; BUZINHANI, M.; YAMAGUTI, M. et al. Intraspecific variation in 16S rRNA gene of Mycoplasma synoviae determined by DNA sequencing. Comp. Immunol. Microbiol. Infect. Dis., v.33, p.15-23, 2010.

GONDAL, M.A.; RABBANI, M.; MUHAMMAD, K. et al. Characterization of Mycoplasma gallisepticum isolated from commercial poultry flocks. J. Anim. Plant. Sci., v.25, p.108-113, 2015.

HUTTON, S.; BETTRIDGE, J.; CHRISTLEY, R. et al. Detection of infectious bronchitis virus 793B, avian metapneumovirus, Mycoplasma gallisepticum and Mycoplasma synoviae in poultry in Ethiopia. Trop. Anim. Health Prod., v.49, p.317-322, 2017.

ISLAM, A.; ASLAM, A.; CHAUDHRY, Z.I. et al. Pathology of Mycoplasma gallisepticum in naturally infected broilers and its diagnosis through PCR. Int. J. Agric. Biol., v.13, p.835-837, 2011.

KIMURA M. A simple method for estimating evolutionary rate of base substitutions through comparative studies of nucleotide sequences. $J$. Mol. Evol., v.16, p.111-120, 1980.

LAUERMAN, L.H.; HOERR, F.J.; SHARPTON, A.R. et al. Development and application of a polymerase chain reaction assay for Mycoplasma synoviae. Avian Dis., v.37, p.829-834, 1993.
MUHAMMAD, F.; HUSSAIN, J.; FAREED, S.K. et al. Diagnosis of avian mycoplasmas: a comparison between PCR and culture technique. Arch. Razi Inst., v.73, p.239-244, 2018.

NASCIMENTO, E.R.; PEREIRA, V.L.A. Micoplasmoses. In: BERCHIERI Jr, A.; SILVA, E.N.; Di FÁBIO, J. et al. Doenças das aves. 2.ed. Campinas: FACTA, 2009. p.485-500.

NASCIMENTO, E.R.; PEREIRA, V.L.A.; NASCIMENTO, M.G.F.; BARRETO, M.L. Avian mycoplasmosis update. Rev. Bras. Cienc. Avic., v.7, p.1-9, 2005.

NASCIMENTO, E.R.; YAMAMOTO, R. Simplification of Mycoplasma gallisepticum polymerase chain reaction. In: WESTERN POULTRY DISEASE CONFERENCE, 40., 1991. Proceedings... [s.1.]: WPDC, 1991. p.9495 .

NOEL-FERGUSON, N. Mycoplasmosis. In: SWAYNE, D.E.; GLISSON, J.R.; MCDOUGALD, L.R. et al. Diseases of poultry. 13.ed. Ames, Iowa: John Wiley \& Sons, Inc., 2013. p.875-876.

NOEL-FERGUSON, N.; NOORMOHAMMADI, A.H. Mycoplasma synoviae Infection. In: SWAYNE, D.E.; GLISSON, J.R.; MCDOUGALD, L.R. et al. Diseases of poultry. 13.ed. Ames, Iowa: John Wiley \& Sons, Inc., 2013. p.900-906.

POVEDA, J.B. Biochemical characteristics in Mycoplasma identification. In: MILES, R.; NICHOLAS, R. Mycoplasma protocols: methods in molecular biology. v. 104, 330p., Totowa, New Jersey: Humana Press Inc., 1998. p. 69-78.

RAVIV, Z.; LEY, D.H. Mycoplasma gallisepticum infection. In: SWAYNE, D.E.; GLISSON, J.R.; MCDOUGALD, L.R. et al. Diseases of poultry. 13.ed. Ames, Iowa: John Wiley \& Sons, Inc., 2013. p.877-893.

RAZIN, S.; YOGEV, D.; NAOT, Y. Molecular biology and pathogenicity of mycoplasmas. Microbiol. Mol. Biol. Rev., v.62, p.1094-1156, 1998.

RELATÓRIO anual 2018, 2019. São Paulo: ABPA Disponível em: <http://abpabr.com.br/storage/files/relatorio-anual2018.pdf>. Acessado em: 22 out. 2019. 
ROSENGARTEN, R.; BEHRENS, A.; STETEFELD, M. et al. Antigen heterogeneity among isolates of Mycoplasma bovis is generated by high-frequency variation of diverse membrane-surface proteins. Infec. Immun., v.62, p.5066-5074, 1994.

ROSENGARTEN, R.; YOGEV, D. Variant colony surface antigenic phenotypes within Mycoplasma strain populations: implications for species identification and strain standardization. J. Clin. Microbiol., v.34, p.149-158, 1996.

SAMBROOK, J.; FRITSCH, E.F.; MANIATIS, T. Molecular cloning: a laboratory manual. 2.ed. New York: Cold Spring Harbor Laboratory Press, 1989. v.2, cap.14.

SID, H.; BENACHOUR, K.; RAUTENSCHLEIN, S. Co-infection with multiple respiratory pathogens contributes to increased mortality rates in algerian poultry flocks. Avian Dis., v.59, p.440-446, 2015.

TAMURA, K.; STECHER, G.; PETERSON, D. et al. MEGA6: molecular evolution. Genetics analysis. Version 6.0. Mol. Bio. Evol., v.30, p.2725-2729, 2013.
TEIXEIRA, V.C.M.; BAPTISTA, D.Q.; CARLOS, F.C. et al. Situação epidemiológica da micoplasmose aviária no Estado do Rio de Janeiro. Braz. J. Vet. Med., v.37, p.379-385, 2015.

UMAR, S.; MUNIR, M.T.; UR-REHMAN, Z. et al. Mycoplasmosis in poultry: update on diagnosis and preventive measures. Worlds Poult. Sci. J., v.73, p.17-28, 2017.

UPHOFF, C.C.; DREXLER, H.G. Comparative PCR analysis for detection of mycoplasma infections in continuous cell lines. In Vitro Cellular \& Developmental Biology Animal. v.38, p.79-85, 2002.

YOGEV, D.; ROSENGARTEN, R.; WATSON, M.R. et al. Molecular basis of mycoplasma surface antigenic variation a novel set of divergent genes undergo spontaneous mutations of periodic coding region and 5' regulatory sequences. EMBO J., v.10, p.4069-4079, 1991. 